\title{
Recensión
}

\section{E. LI'CANO}

Imaginario colectivo y creación matemática. La construcción social del numero, del espacio y lo imposible en China y Grecia. Barcelona: Gedisa, 1993

El libro de Lizcano llegó a mis manos gracias a un colega y excelente amigo que me sugirió —en razón de mi pasado matemático- una lectura atcrita $y$, si fuera posible, una revisión crírica escrita sobre el mismo. Pasado el fielato del prólogo (tómese más bien como epílogo) me dediqué a hojearlo por ese compromiso, pues el tema caía lejos de mis preocupaciones del momento. (Ya se sabe "cuán ocupados» estamos los de la fauna académica en temas de trabajo sumamente importantes...) Y bien, el libro no sólo no se me cayó de las manos, sino que ha sido una de las lecturas más estimulantes (término que pese a su carácter de tópico tengo a bien empleas) que he podido hacer úlcimamente.

En mis ricos iniciácicos de sociólogo leí, ;como no! la Invitation to Sociology (1963) de Peter Berger donde el autor debunking (entiéndase "desenmascarar", "demoler", "contraevidencia", etc.). No es ningún secreto que gran parte de la sociologia es profundamente crítica y autocrítica. Dejando en manos de quien proceda la justificación de esto, me he inteesado últimamente por la empresa crítica de la sociología del conocimiento científico en sus versiones de Latour, Woolgar, Knorr y otros. La visión del sociólogo-antropólogo en la "manufacturan de la ciencia se me antoja particularmente atractiva. Justamente es la que impregna la obra de Emmanuel Lizcano. Es un trabajo de etnociencia, de arqueología del saber, de epistemología (comparada y tout court). Es, sobre todo, aquella labor -entrevcrada à son insude uobservadon y "participanten a la vez, lo que me parece ejemplar.

Lizcano acomete la labor de rastrear la aparición del número negativo en la matemácica o, quizás mejor dicho, las taíces culturales subyacentes al concepto de negatividad. Un empeño osado pues, como se detiene a mostrat en su capitulo introductorio, esta "deconstrucción" del edificio racional de la matemática tan -aparentemente- inexpugnable al imaginario colectivo (de aquí el subtítulo del libro) sólo puede hacerse desde posiciones cientificas muy seguras y pertrechado de una artillería retórica (persuasoria) contundente. De entrada, nos enteramos que allá en el lejano Oriente, los chinos "se inventan" el cero y los negativos en el siglo II aC: la matemática europea (heredera del pensamiento griego) los aceptó a regañadientes a partir del siglo $\mathrm{XV}$. ¿Cómo se explica esto? 
Lizcano despliega ante el lecror un díptico deslumbrante en cl que contrapone el modo de pensar (discurso o episteme, como él lo llama) de los chinos y el modo de pensar griego. Su hilo conductor arranca de las concepciones harto diferentes del espacio en China y en Grecia. Allá es un espacio simbólico que, como dice ell, "carga a cada lugar de significadon; un espacio que cuando se plasma en un tablero de cálculo ubica en él montones de palillos materializando umanojos de grano" cuyos precios se calculan a través de puras manipulaciones. Éstas resultarán (con el tiempo) ser el equivalente de resolución de lo que nosotros llamaremos "5istemas de ecuaciones por el método de los determinantes".

En la Grecia mediterránea el espacio es, en cambio, homogéneo y excenso; un espacio determinado por objetos que se perciben y se tocan. Lizcano, citando a Ortega y Gasset, alude a la "sensualidad" griega que abomina del vacío. De ahí que, en la abrupta dicotomía scr/no-ser que establece Parménides, el segundo término es in-pensable, in-proferible, in-concebible. El que más tarde denominaremos "cero" choca frontalmente, cuando pugna por abrirse a la luz, con esta concepción que Lizcano no duda en calificar de creencia (anclada en el imaginario cultural). En ta Grecia clásica el "cero" no fue posible. A fortiori los números negativos. ¿Cómo se va a poder sustraer algo del noser? Cerrando el círculo, está la concepción geometrizante (espacial, extensa) del número. ¿Àreas nulas o negativas?... Pata la episteme griega es una auténtica sinrazón. Por el contrario, en el seno del espacio significante chino, los huecos «tienen lugar", es decir, poseen la calidad de "ser algo" estando este algo determinado por la rclación que guardan con los otros lugares plenos de palilios. En otras palabras, estos últimos y los huecos correlativos no son tanto números cuanto nombres de resultados que se obtienen en el decurso de manipulaciones con aquéllos: palitilos de color rojo, de color negro y "vacíos" son transacciones y transiciones dentro de una prácrica manual que discurte por otros cauces que los pre-juicios griegos acerca de la "esencian del número.

lizcano extiende esra doble incursión en las cosmovisiones china y griega a un casi obligado paraelismo entre el yinhyang y el ser/no-ser que las caracteriza respectivamente. A este propósito escribe (no me resisto a utilizar sus propias palabras): "La barra del par ser/no ser (griego) separa, incomunica ambos hados; al contrario que la del yin/yang. [...] Simetría china, asimetría radical griega. [. . .] La barra griega es intransitiva e intransitable; ni une ni separa ámbitos homogéneos; no existe elemento identificable que pudiera ejercer de quicio que articule la interacción del no-ser y ser como $w u$ (el "cero") articula la acción recíproca del yin/yang (p. 155).

Es, por otro lado, sorprendente que en dos o tres momentos históricos asoma el "fantasma" de la negatividad en la Grecia clásica o, al menos, las elucubraciones de algunos de sus genios (Anaximandro, Demócrito o más tarde Diofanto) la tantean o la cortejan en la obscuridad de su radical incapacidad para designarla. Sin embargo, el peso de los argumentos de Aristóteles cae como una losa sobre la puerta de la libercad creadora que se mantiene en deçà de los límitcs que el imaginario cultural le ha marcado. Lizcano no lo afirma pero uno tiene la impresión de que, ya desde entonces, el que unas ideas triunfen y persistan como "verdaderas" (o científicas) es cuestión de retórica: argumentos y argumento de autoridad. (p. 172-174). Lo que si encontraba más confortablemente acomodado en el horror al vacio, en la primacía de lo sensible, que no en la dialéctica o la recursividad necesaria para imaginar el no-ser como ser.

Mi transcripción entrecortada de la resis de Lizcano es, si no infiel a sus ideas, desoladoramente incompleta. Porque no es tanto este núcleo o hillo conductor lo 
que la hace notable, sino la articulación tan coherente de sus argumentos, la documentada fundamentación de sus opiniones y la exploración del ámbito cultural que hace posible/imposible la "resurgencia" del cero y los negativos. Del pensamiento griego sabemos mucho (inconscientemente y conscientemenre), pero de los chinos, de su lenguaje, de su concepción del espacio y del tiempo, del sutil juego de su pensamiento y la literatura que hacen de las simetrlas, inversiones $i$ reflexiones (especulares) apenas sabíamos nada (tampoco los maoístas furibundos de los gloriosos $68 \ldots$ ). Lizcano esboza de la mentalidad china un fresco caleidoscópico y deslumbrante. El engarce que propone entre la escritura ideográfica, el pensar chino, el tablero de cálculo y las oposiciones articuladoras de "lo positivo/lo negativo" (iperdón por este anacronismo!) vale la pena, casi ello solo, la leccura del libro. Es como un viaje de antropólogo por otras mentes, otros modos de concebir el mundo que nos dejan "descolocados" en nuestra ingenua pretensión del valor "supremo e incontestable" de la racionalidad occidental, engreida heredera del pensamiento griego.

Finalmente, señalar la actitud de surveillance épistémologique que marca inexorablemente la exposición de Lizcano. Adopta, como dije antes, el papel del antropólogo: un uobservador" y también participante. Trata primorosamente de no contaminar, con juicios de un saber nacido siglos después, el quehacer del "algebrista" chino; explora (no sin cierto regusto irónico) los recovecos del discurso griego y logra, gracias a un uso muy depurado del lenguaje (de los recursos dc indexicalización), hacernos penetrar $y$ degustar dos núcleos de civilización tan extraños el uno al otro. Mi revisión creo que traduce sin ambages el placer que me ha deparado esta lectura. Mi versión, sin embargo, no incluye la critica de aspectos técnicos que afectarían, quizás, a tal o cual interpretación de textos chinos o helénicos a los que recurre Lizcano. Escapa a mi competencia juzgar si "están todos los que son y son todos los que están». La coherencia interna del tratado de Lizcano, que encomio sin reservas, debería -bien lo sé- quedar engastada en un cxamen atento de la pertinencia de las fuences en que se basa. Este libro es la versión - tengo entendido que apenas modificada - de la tesis doctoral del autor. Tesis como esta son un motivo de orgullo para la ciencia española y ponen una nota de optimismo frente al panorama de trivialidades con que nos castiga el apresuramiento de los doctorandos y la transigencia de algunos parrocinadores de tesis en este país.

Adolfo Perinat Departamento Pscicología de la Educación. UAB 